J. Lake Sci.(湖泊科学), 2019, 31(2): 539-550

DOI 10. 18307/2019. 0222

(c) 2019 by Journal of Lake Sciences

\title{
内蒙古高原达里诺尔湖夏季水体稳定同位素变化特征
}

\author{
李文宝, 刘志娇, 杨 旭, 李畅游 \\ (内蒙古农业大学水资源保护与利用自治区重点实验室,呼和浩特 010018)
}

\begin{abstract}
摘 要: 基于内蒙古高原寒一早区达里诺尔湖 (简称“达里湖”) 相对集中的夏季大气降水、强烈的蒸发作用等典型区域气 候环境特征, 结合湖泊水体温度、盐度等理化指标变化, 对夏季达里湖湖水、人湖河水、区域大气降水等样品中稳定氢、氧 同位素 $\left(\delta \mathrm{D} 、 \delta^{18} \mathrm{O}\right)$ 值变化进行了对比分析. 结果显示: 虽然整体上达里湖夏季水体并没有形成明显的物理性质 “跃层” (如温跃层、盐跃层等), 水体理化指标的空间分布相对稳定, 但是夏季湖水中 $\delta \mathrm{D} 、 \delta^{18} \mathrm{O}$ 值却随着水深增加逐渐偏负: $\delta \mathrm{D}$ 值由表层水体 $(0 \sim 1 \mathrm{~m})$ 到底层水体 $(7 \sim 9 \mathrm{~m})$ 偏负约 $1.40 \%$, $\delta^{18} \mathrm{O}$ 值由表层水体到底层水体偏负约 $0.27 \%$. 达里湖夏季 “大气水线” 为 $\delta \mathrm{D}=8.22 \delta^{18} \mathrm{O}+6.82$, 显示大气降水中 $\delta \mathrm{D} 、 \delta^{18} \mathrm{O}$ 值受季风降水效应影响的同时受到区域蒸发作用影响. 特 别是 $7 、 8$ 月大气降水同位素变化受降水效应的影响比 6.9 月更明显, 而 6.9 月大气降水同位素变化受蒸发作用的影响比 $7 、 8$ 月更明显. 这也导致达里湖夏季上层水体受大气降水的稀释作用影响显著; 伴随水深的增加,降水效应及蒸发作用的 混合影响逐渐减弱, 底层水体受区域地下水补给过程等因素的影响则可能更加明显, 即达里湖夏季上层水体和底层水体 中稳定同位素组成变化的影响因素存在差异.
\end{abstract}

关键词: 氢同位素;氧同位素;水文过程;夏季;达里诺尔湖

\section{Changes of stable oxygen and hydrogen isotopes in summer Dali-nor Lake in Inner Mon- golia of Northern China}

\author{
LI Wenbao, LIU Zhijiao, YANG Xu \& LI Changyou \\ (IMAR Key Laboratory of Water Resources Protecting and Utilization, Inner Mongolia Agricultural University, Hohhot \\ 010018, P.R.China)
}

\begin{abstract}
As one proxy of water evolution, hydrologic cycle and water balance in lakes, the stable isotopes of hydrogen and oxygen ( $\delta \mathrm{D}$ and $\delta^{18} \mathrm{O}$ ) had been wildly utilized during lake researching. However, one problem is that a few works based on stable isotopes of lake water had been done in Cold-Arid regions of China. In this paper, to analyze the relationships of $\delta \mathrm{D}$ and $\delta^{18} \mathrm{O}$ and their feedbacks on precipitation process and vaporization process, totally 144 samples of lake water, river water and precipitation water had been collected in summer Dali-nor Lake, which locates in Cold-Arid area of Inner Mongolia, North China. Meanwhile, the typical physical and chemical proxies of lake water had been measured, such as temperature, salinity, pH value, and so on. By comparing the values of $\delta \mathrm{D}$ and $\delta^{18} \mathrm{O}$ among different types of sample, we concluded that: The values of classical physical and chemical proxies of lake water offset a certain degree following depth change, and are also a little different between different regions at the same water depth. But there are no clearly fluctuations appeared, such as thermocline and halocline, in summer Dali-nor Lake. As a whole, the characteristics of water mass are essentially stable in summer Dali-nor Lake. But, the values of $\delta \mathrm{D}$ and $\delta^{18} \mathrm{O}$ both become lighter and lighter following water depth changing. For example, the value of $\delta \mathrm{D}$ and $\delta^{18} \mathrm{O}$ are about $-31.723 \%$ and $-1.785 \%$ in surface water, and about $-31.776 \%$ and $-1.838 \%$ in bottom water, respectively. The meteoric water line is $\delta \mathrm{D}=$ $8.22 \delta^{18} \mathrm{O}+6.82\left(R^{2}=0.936, n=42\right)$, which shows that the change of $\delta \mathrm{D}$ and $\delta^{18} \mathrm{O}$ in precipitation had influenced both by rainfall process and vaporization process in Dali-nor Lake. The precipitation may have stronger influence on fractional distillation of $\delta \mathrm{D}$ and $\delta^{18} \mathrm{O}$ than evaporation process in July and August. Correspondingly, the evaporation process may have stronger influence on fractional distillation of $\delta \mathrm{D}$ and $\delta{ }^{18} \mathrm{O}$ than precipitation process in June and September. As a result, the relationships of $\delta \mathrm{D}$ and
\end{abstract}

* 国家自然科学基金项目 (51469025,51669021,51709162) 和内蒙古自治区自然科学基金项目 (2016MS0552, 2016MS0406) 联合资助. 2018-07-09 收稿; 2018-09-09 收修改稿. 李文宝 (1980 ) , 男,博士, 副教授; E-mail: tianshiTD@126.com. 
$\delta^{18} \mathrm{O}$ in surface water and bottom water are different in summer Dali-nor Lake. The relationship in surface water is nearly with those in precipitation and river water, but the relationship of bottom water is close to those in groundwater. Resumptively, the value changes of $\delta \mathrm{D}$ and $\delta^{18} \mathrm{O}$ in surface water might be influenced mainly by evaporation process and precipitation process, and those might be influenced mainly by groundwater input in deeper water.

Keywords: $\delta \mathrm{D} ; \delta^{18} \mathrm{O}$; hydrologic cycle; summer; Dali-nor Lake

湖泊是区域水循环系统中的重要组成部分, 不仅是地表系统各要素相互作用的节点, 而且是重要的区 域水资源库,对外界条件的改变反应极其灵敏. 现代湖泊区域环境演化不仅与人类的生存发展息息相关,在 维系流域生态平衡等方面也发挥着不可替代的作用 ${ }^{[1-3]}$. 一旦湖泊水量平衡、水体环境被破坏, 将会对区域 生态环境等产生严重影响 ${ }^{[4-5]}$. 因此, 进行湖泊水体演化过程研究, 分析湖泊水体环境变化及水量、水质等问 题已经成为现代湖泊学研究的重要方向之一 ${ }^{[6-8]}$. 目前, 利用水体稳定氢 $(H)$ 、氧 $(O)$ 同位素值 $\left(\delta D 、 \delta^{18} O\right)$ 进 行湖泊水体物质迁移过程、水量平衡及水文循环的分析研究已经广泛开展 ${ }^{[9-16]}$. 例如, 前期研究发现, 结冰过 程往往是寒早区湖泊水体 $\delta \mathrm{D} 、 \delta^{18} \mathrm{O}$ 值变化的主要影响因素之一 ${ }^{[17]}$, 同时强烈的蒸发作用也是高纬度寒一旱 区湖泊有别于低纬度湿润区域湖泊水文循环过程的典型影响因素 ${ }^{[18]}$. 整体上, 在区域水文循环演变过程 中, 中国北方寒一早地区湖泊除受流域水文特征及湖水滞留时间等因素的影响外 ${ }^{[19-20]}$, 相对集中的夏季大气 降水、强烈的蒸发作用、漫长的冬季结冰期等也成为湖泊水文特征、湖水稳定同位素组成及区域水文循环过 程的典型影响因素 ${ }^{[20-22]}$. 遗憾的是, 针对中国北方寒一旱区湖泊开展的水体稳定同位素研究,特别是基于水 体中 $\delta \mathrm{D} 、 \delta^{18} \mathrm{O}$ 值变化进行湖泊水文循环等相关过程分析的研究工作却比较少见, 这对进行不同气候条件下 的区域水文循环特征对比,分析中国南、北方不同区域的湖泊水文循环变化特征及影响因素差异造成不便.

在中国北方寒一旱区, 湖泊每年主要经历冰封期和非冰封期两个阶段: 冰封期寒冷漫长, 如内蒙古达里 诺尔湖 ( 以下简称 “达里湖”) 在每年 11 月底即完成全部结冰封湖, 来年 4 月上旬才逐渐融冰开湖, 期间湖水 被巨厚的湖冰覆盖, 湖水流动几乎停滞, 水体与外界交换缓慢 ${ }^{[20,23]}$; 相对地, 在非冰封期, 失去冰盖的阻挡, 湖水与外界交换逐渐频繁, 特别是夏季集中的大气降水往往为湖泊带来补给, 而相对强烈的蒸发作用又会 带走大量的水分, 湖水理化性质变化相对活跃. 因此, 夏季湖泊水体性质变化特征的分析相对更具有水文学 意义,也将为分析达里湖上层水体与下层水体稳定同位素组成变化的主要水文学影响因素差异提供基础.

基于此, 本文以内蒙古高原达里湖为研究目标区域, 通过以水体交换相对频繁的夏季作为研究时段, 采 集达里湖不同位置不同深度湖水、入湖河水及大气降水等水体样品, 分析样品中稳定 $\mathrm{H} 、 \mathrm{O}$ 同位素的变化特 征, 同时结合夏季湖水不同深度的温度、盐度、溶解物质含量 (TDS) 等理化指标的变化, 对达里湖夏季水体 稳定同位素的富集或贫化规律及影响因素进行分析, 这将为进一步研究寒一早区湖泊水文循环、元素迁移等 过程提供理论参考.

\section{1 达里湖区域概况}

达里湖 ( $43^{\circ} 12^{\prime} \sim 43^{\circ} 24^{\prime} \mathrm{N}, 116^{\circ} 24^{\prime} \sim 116^{\circ} 56^{\prime} \mathrm{E}$ ) 位于内蒙古自治区赤峰市克什克腾旗境内, 南临浩瀚的 浑善达克沙地, 西北方向为锡林郭勒大草原, 东侧为贡格尔草原, 是内蒙古东部重要的水资源地. 在地理学 意义上, 达里湖位置关键, 位于东亚夏季风的北部边缘, 区域大气降水变化主要受到东亚夏季风影响, 全年 降水量的一半以上集中在夏季 ${ }^{[24-25]}$; 又是中国北方寒一旱区典型的高原内陆湖泊 (图 1), 年均冰封期长达 $4 \sim 5$ 个月. 湖区年均降水量约为蒸发量的 $1 / 3$ 且主要集中在夏季; 其中 7 月最热, 平均气温为 $16 \sim 18^{\circ} \mathrm{C}^{[25]}$.

目前, 达里湖面积约为 $189 \mathrm{~km}^{2}$, 湖水由东南向西北逐渐变浅, 最深处约 $13 \mathrm{~m}^{[23,26]}$, 湖水补给来源主要为 大气降水、河流输人及地下水补给等, 无河流外泄, 湖水排泄方式主要为蒸发. 现在共有 4 条河流人达里湖, 分别为: 亮子河、沙里河、耗来河与贡格尔河 (图 1). 其中补给量最大的是发源于大兴安岭尾脉阿拉烧哈山 脉的贡格尔河, 总长 $120 \mathrm{~km}$, 由北部人湖; 沙里河发源于克什克腾旗经棚镇西侧, 流程 $25 \mathrm{~km}$, 由南部人湖; 亮子河发源于湖的南部沙丘地带, 由西南部人湖; 耗来河发源于西部丘陵, 由西部人湖 ${ }^{[23]}$. 其中亮子河与贡 格尔河为主要人流河, 沙里河与耗来河均受季节变换影响明显. 不同年份, 4 条河流年输人湖泊的水量也存 在差异. 整体上,达里湖不仅具有调节区域气候, 为鸟类提供栖息地, 为人类提供丰富渔业、旅游资源等多种 


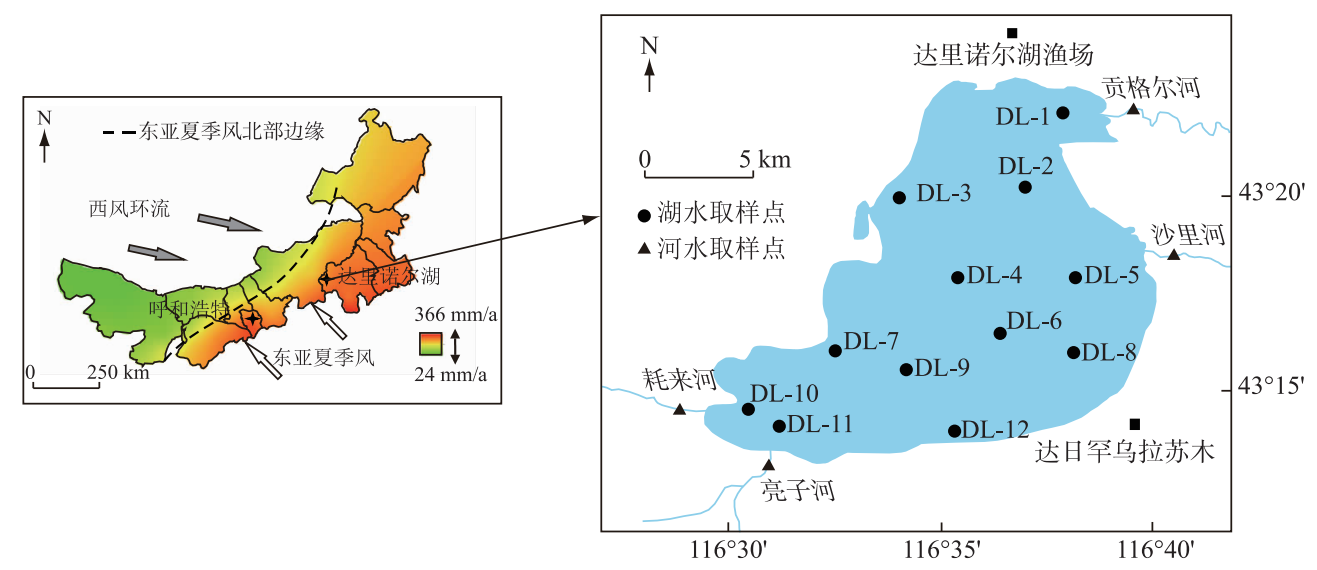

图 1 达里湖夏季湖水取样点位置示意 (左图为内蒙古中部近 60 年以来的年均降水量, 数据来源于中国气象科学数据共享服务网 http://cdc. cma.gov.cn/shuju/preview.jsp ${ }^{[24-25]}$.)

Fig.1 Sample locations of the summer water in Dali-nor Lake

功能,而且是区域水文循环中各个要素相互影响的重要交汇点.

\section{2 材料与方法}

基于达里湖区域地形地貌特征、现代水文地质 条件以及人湖河流的河口位置等要素特征,共在湖 内布设 12 个取样点, 由北到南依次为: DL-1、DL-2、 DL-3、DL-4、DL-5、DL-6、DL-7、DL-8、DL-9、DL-10、 DL-11、DL-12（图 1, 表 1)，其中 DL-1、DL-5、DL-10、 DL-11站点依据河口位置布设. 本文样品主要为 2017 年 8 月中旬所取达里湖湖水、人湖河流水体样 品及 2013 年以来 6-9 月所采集的湖区大气降水样 品 (根据达里湖大气降水变化, 本文以 6 月中下旬到 9 月上旬作为夏季阶段), 同时参考部分已发表数据. 具体采样方法为: 湖泊水样利用船舶直接在采样点 进行采集, 根据湖泊地形地貌特征及各站点水深变 化情况, 在 DL-4、DL-5、DL-9 和 DL-11 4 个水深较大 的取样点以 $0.5 \mathrm{~m}$ 间隔采集湖水样品, 4 个站点共计 采集 69 个样品,其他 8 个取样点则以 $1 \sim 1.5 \mathrm{~m}$ 间隔 进行样品采集 (由于 DL-1 点水深较浅, 以 $0.5 \mathrm{~m}$ 间隔取样), 共计采集样品 29 个. 人湖河水样品在距河流人 湖口约 $1 \mathrm{~km}$ 处进行采集, 共采集 4 个样品. 湖水及河水每次采集约 $100 \mathrm{ml}$; 大气降水样品利用标准集雨器 于空旷的室外, 在每次降水过程中采集雨水 1 次, 根据实际降水量采集约 $50 \sim 100 \mathrm{ml}$, 共采集大气降水样品 42 个. 需要注意的是样品采集完成后需立即密封保存在聚乙烯瓶中, 并尽快完成测试工作.

水体样品中 $\delta \mathrm{D} 、 \delta^{18} \mathrm{O}$ 值采用美国 Los Gatos Research (LGR) 公司生产的液态水同位素分析仪(型号: DLT-100) 进行测定 ${ }^{[7,20]}$. 样品在分析测试之前需要经 $0.45 \mu \mathrm{m}$ 的滤膜过滤 $3 \sim 4$ 次, 每个样品测试 6 次, 取后 4 次测试结果的平均值. 样品测试结果均经过国际原子能机构 (IAEA) 的 VSMOW 标准样品进行校正. 测试 精确度: $\delta^{18} \mathrm{O} \%$ 误差不大于 $0.1 \%$, $\delta \mathrm{D} \%$ 误差不大于 $0.3 \%$. 水体样品的分析测试工作均在内蒙古农业大学水 资源保护与利用自治区重点实验室完成.

此外, 在各取样点对不同深度水体的部分典型理化性质指标进行测定:如利用梅特勒一托利多公司生产 
的多参数水质监测仪对湖水中溶解氧、pH 值、盐度、电导率等指标进行现场测定; 利用 HXH03-1 型超声波 多普勒流速流向仪对水体不同深度流速、流向等进行测定. 各个参数测定精度以所采用实验仪器标定为准, 不再累述 ${ }^{[23]}$. 具体测定过程为: 湖水温度、流速等指标在 DL-4、DL-5、DL-9 和 DL-11 4 个样点以 $0.25 \mathrm{~m}$ 间隔 进行测定, 在其他站点则根据具体水深变化, 采用 $1 \sim 1.5 \mathrm{~m}$ 水深间隔测定; 湖水溶解氧浓度、盐度、 $\mathrm{pH}$ 值、 TDS 等指标均以 $0.5 \mathrm{~m}$ 水深间隔进行测定.

\section{3 结果}

\section{1 达里湖夏季水体典型理化指标变化特征}

作为内陆封闭性湖泊, 达里湖夏季水体理化性质的各典型代表指标随深度增加并没有出现明显的改变. 不过, 由于夏季湖泊水体交换相对频繁, 受外部环境变化影响明显, 导致不同取样点上反映水体性质的理化 指标的具体变化特征却并不一致.

首先, 湖泊表层水体由于受到太阳辐射、大气降水、河流输人等外界因素的直接影响, 导致达里湖表层 水体的温度、盐度、TDS 等理化指标的区域变化差异明显, 不同取样点间的差异比底层水体更加明显: 如表 层湖水温度的变化范围为 $13.3 \sim 17.5^{\circ} \mathrm{C}$, 而底层湖水的温度变化范围为 $14.4 \sim 16.5^{\circ} \mathrm{C}$ ( 图 2). 特别地, 虽然湖 泊水体的流动速度和方向对不同区域间的湖水交换过程有着重要的影响作用, 但是达里湖水体流动缓慢, 平均流速只有约 $0.15 \mathrm{~m} / \mathrm{s}$, 且不同区域间的水体流速差异较小, 因此湖水流动对达里湖水体交换的影响可能 较弱 ${ }^{[23]}$ (图 2). 其次, 不同取样点间水体理化指标的垂向变化特征也存在一定程度的差异. 对比 DL-4、 DL-5、DL-9 和 DL-11 水深较大的取样点, 可以发现: DL-4 取样点的水体温度均低于相同水深的达里湖平均 值, 但是 $\mathrm{pH}$ 值却均高于平均值, 其他理化指标则在平均值附近波动; DL-9 取样点温度、湖水流动速度、 $\mathrm{pH}$ 值略高于相同水深处的平均值. 而 DL-9 取样点湖水盐度、TDS 及溶解氧浓度在上层水体中略高于平均值, 且随着水深增加而逐渐减小, 但在底层水体中低于平均值; 在 DL-11 取样点, 由于可能受到人湖河流水体输 人的影响, 其水体 $\mathrm{pH}$ 值、溶解氧浓度均比湖水平均值小. 湖水流速由上层水体大于平均流速逐渐变缓, 底层 水体的流速小于平均流速. 温度、盐度和 TDS 浓度则基本分布在湖水平均值附近; DL-5 取样点的水体流速 和 $\mathrm{pH}$ 值均略低于湖泊水体的平均流速和 $\mathrm{pH}$ 值, 而溶解氧浓度则略高于平均值. 相对地, DL-5 取样点不同 深度水体的温度、盐度和 TDS 浓度等均在湖水平均值附近波动. 当然, 其他取样点水体的理化指标也存在一 定程度的区域差异变化,但均没有出现明显的偏移 (图 2).

整体上, 在不同取样点, 不同湖水理化指标随着水深变化出现一定程度的偏移, 且同一深度不同取样点 的水体典型理化指标也存在一定程度的差异. 不过, 由于达里湖水深较浅, 这种偏移或差异的程度并没有形 成明显的 “跃层” (如温跃层、盐跃层等). 因此, 可以说达里湖夏季水体的典型理化性质整体上是相对稳定 的, 不存在明显的垂向或水平方向上的空间变化, 这也为分析达里湖湖泊水体中 $\delta \mathrm{D} 、 \delta^{18} \mathrm{O}$ 值变化特征及影 响因素提供了比较理想的条件.

\section{2 达里湖夏季大气降水同位素组成特征}

由于地理位置及气候条件的差异, 不同区域间大气降水的同位素组成比例存在一定差异, 而根据大气 降水稳定同位素关系建立的方程式被称为 “大气水线”. 如表示全球大气降水中 $\delta \mathrm{D} 、 \delta^{18} \mathrm{O}$ 值变化特征的 “全 球大气水线” 表达式为 $\delta \mathrm{D}=8.14( \pm 0.02) \delta^{18} \mathrm{O}+10.9( \pm 0.02)^{[27-28]}$. 当然,近年来国内不同区域的“大气水线” 也已经被广泛建立,显示我国不同区域大气降水的同位素组成受到温度效应、降水效应等不同因素的影 响 ${ }^{[24,29-32]}$,这也为分析达里湖区域大气降水的稳定同位素组成提供了理论支持.

一般来讲, 可以用 “大气水线” 的斜率指示大气降水过程中水体形态变化, 用截距指示水汽运输过程中 的平衡状态. 不过, 不同区域间地理位置 (纬度、海拔等)、大气温度、降水过程等因素都会对区域 “大气水 线” 产生影响 ${ }^{[30,33-35]}$, 而这些影响往往表现在区域“大气水线” 的斜率和截距偏移上. 例如, 在干旱地区, 由于 强烈的蒸发作用, “大气水线” 的斜率和截距往往会出现一定程度的减小 ${ }^{[36-38]}$. 在达里湖区域, 根据 $2013-$ 2017 年夏季大气降水样品中 $\delta \mathrm{D}$ 和 $\delta^{18} \mathrm{O}$ 值的关系建立的 “大气水线” 表达式为 $\delta \mathrm{D}=8.22 \delta^{18} \mathrm{O}+6.82\left(R^{2}=\right.$ 0.936) (图 3a). 显然, 达里湖夏季 “大气水线” 的斜率 (8.22) 比较接近全球 “大气水线” 的斜率, 显示东亚夏 季风降水效应的影响; 同时,截距 (6.82) 又明显较低, 显示了二次蒸发作用对大气降水同位素组成的影 


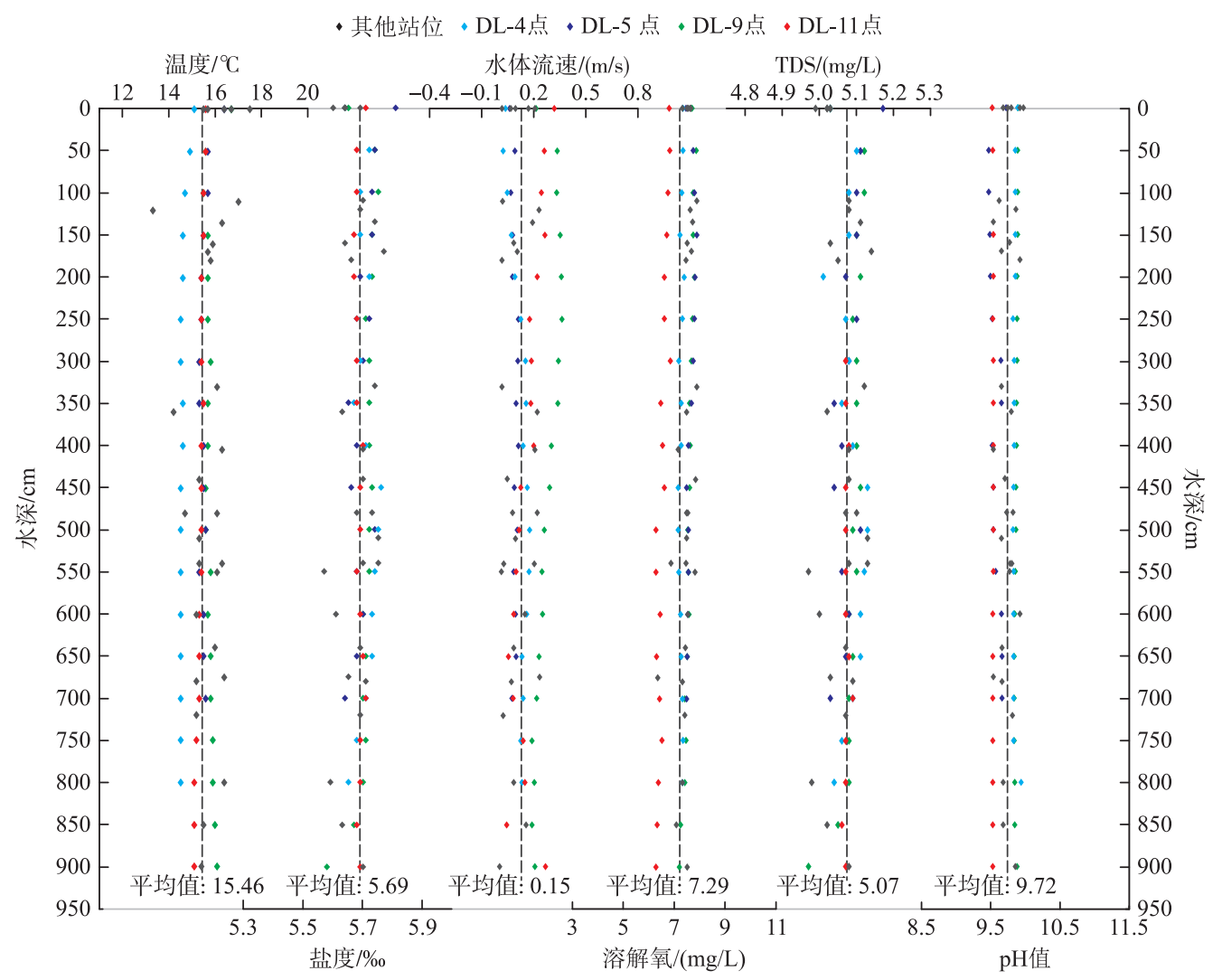

图 2 达里湖不同深度水体部分典型理化指标变化特征

(图中纵向黑色段划线代表达里湖夏季水体各个理化指标的平均值)

Fig.2 Physical proxy changes in different depths in summer water in Dali-nor Lake

响 $^{[30]}$ (图 3a). 在地理位置上, 达里湖位于东亚夏季风的北部边缘, 区域大气降水受到东亚夏季风的影响 (图 $1)$, 夏季降水量占到全年降水量的 $50 \%$ 以上 ${ }^{[24-25]}$; 又是中国北方寒一旱区典型的内陆湖泊,年均蒸发量远大 于年均降水量 ${ }^{[23]}$. 因此达里湖夏季 “大气水线” 特征对应了其典型的地理位置特征, 即表现出一定程度的季 风降水效应 (位于东亚季风区边缘) 又显示了蒸发作用 ( 又是处于中国北方寒一早区) 的影响.

此外,根据 “大气水线” 截距和斜率关系, Dansgarrd ${ }^{[39]}$ 提出的氞盈余指数 $(d)$ 则指示了大气降水过程中 再蒸发作用的强弱. 一般来讲, 大气降水中 $d$ 值的变化除受到水汽来源因素的影响外, 大气降水强度 (降水 效应）、大气温度 (蒸发作用) 等作用也是影响 $d$ 值的关键因素 ${ }^{[34,38]}$. 虽然 $7 、 8$ 月达里湖的平均气温比 $6 、 9$ 月 高, 但是 7、8 月的大气降水量相对 6、9 月的大气降水量则更多 ${ }^{[23-24]}$, 显然 7、8 月大气降水同位素的组成受到 强烈蒸发作用影响的同时又受到全年最强降水效应的影响, 这导致达里湖大气降水中 $d$ 值在 $7 、 8$ 月出现明 显下降,即夏季集中的大气降水过程在 7、8 月成为达里湖区域显著的气候要素, 使得蒸发作用对大气降水 $d$ 值的影响作用相对减弱, $d$ 值出现明显负偏移 ${ }^{[23,40]}$; 而在 $6 、 9$ 月, 由于大气降水强度减弱, 蒸发作用相对较 强, 则导致蒸发作用对大气降水 $d$ 值的影响作用相对增强, $d$ 值出现明显偏正 ( 图 3b).

整体上,夏季 “大气水线” 特征及不同月份大气降水中 $d$ 值出现的明显偏移显示出达里湖夏季大气降 水中 $\delta \mathrm{D} 、 \delta^{18} \mathrm{O}$ 值即受季风降水效应影响又受区域蒸发作用影响: 7、8 月份大气降水同位素组成相对受季风 降水的稀释效应影响更强烈, 而 $6 、 9$ 月则相对受区域蒸发作用的浓缩效应影响更强烈. 因此, 作为达里湖主 要补给源之一, 夏季大气降水中 $\delta \mathrm{D} 、 \delta^{18} \mathrm{O}$ 值的变化会对湖水同位素组成产生一定程度的影响. 

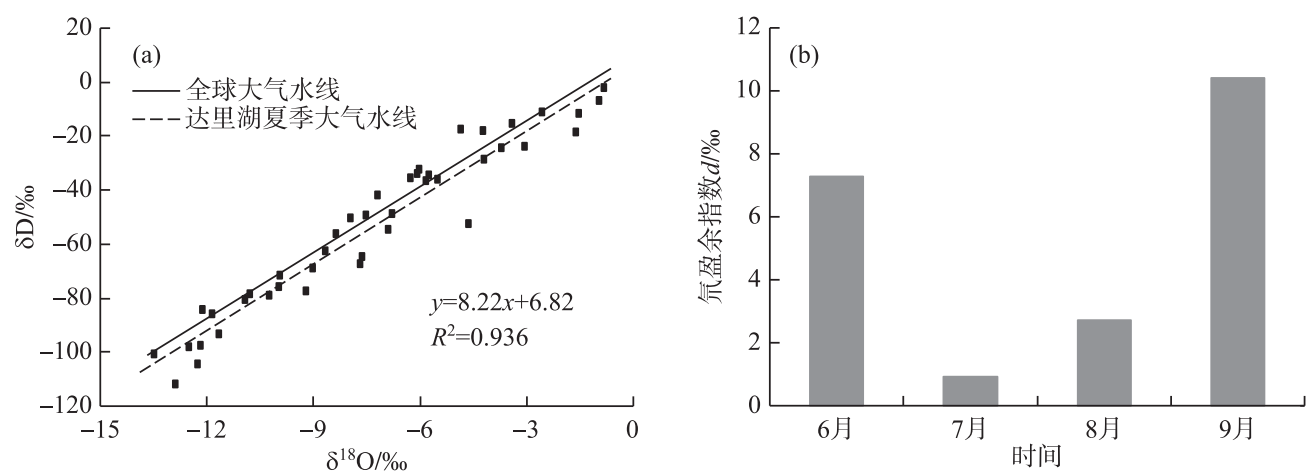

图 3 达里湖夏季大气降水稳定同位素变化

（ (a) 达里湖区域夏季 “大气水线”; (b) 达里湖夏季各月份大气降水中 $d$ 值变化)

Fig. 3 Stable isotope variations in summer precipitation in Dali-nor Lake

\section{3 达里湖夏季水体同位素垂向变化特征}

达里湖水体由东北向西南逐渐变深, 最深处约为 $13 \mathrm{~m}$, 平均水深只有约 $6.4 \mathrm{~m}^{[26]}$. 在强烈蒸发作用下, 湖水深度受到大气降水、河流输人、地下水补给等因素的综合影响, 往往出现一定幅度的波动. 本文涉及的 12 个取样点中, DL-11 点水深最深, 平均约为 $9.0 \mathrm{~m}$; DL-1 点水深最浅, 平均约为 $1.3 \mathrm{~m}$ (表 1). 根据具体水 深变化及采样间隔, 分别对取样较密的 DL-4、DL-5、DL-9 和 DL-11 取样点 $\delta \mathrm{D} 、 \delta^{18} \mathrm{O}$ 值随水深变化情况进行 详细讨论, 而对其余 8 个取样点水体中 $\delta \mathrm{D} 、 \delta^{18} \mathrm{O}$ 值进行综合分析. 在此, 基于达里湖水体相对稳定的理化特 性, 根据不同深度湖水受大气降水、二次蒸发及河流、地下水补给等因素影响程度的差异, 本文指定深度 $0 \sim$ $1 \mathrm{~m}$ 水体作为上层水体、深度 4 5 $\mathrm{m}$ 水体作为中层水体、深度 7 9 $\mathrm{m}$ 水体作为底层水体, 在此基础上对达里 湖夏季水体中 $\delta \mathrm{D} 、 \delta^{18} \mathrm{O}$ 值的垂向变化进行分析.

随着深度的增加, 湖泊水体中 $\delta \mathrm{D} 、 \delta^{18} \mathrm{O}$ 值出现一定程度的偏负, 当然不同站点水体的同位素值的偏移 程度并不一致 (图 4). 整体来看: 由上层水体 $(0 \sim 1 \mathrm{~m})$ 到中层水体 $(4 \sim 5 \mathrm{~m})$, 多数取样点的 $\delta \mathrm{D} 、 \delta^{18} \mathrm{O}$ 平均值 出现不同程度的偏负 (由于 DL-11 点上部样品实验处理过程中受到污染, 故实验数据无效, 表 2). 不过, 在 DL-9 点, 水体稳定同位素值由上层水体到中层水体, $\delta^{18} \mathrm{O}$ 平均值却出现约 $0.03 \% 0$ 的偏正 (表 2 , 当然如考虑 到仪器误差, 可以忽略); 由中层水体 $(4 \sim 5 \mathrm{~m})$ 到底层水体 $(7 \sim 9 \mathrm{~m})$, 全部取样点湖水中 $\delta \mathrm{D}$ 平均值依然出 现不同程度的偏负, 而不同取样点 $\delta^{18} \mathrm{O}$ 平均值的变化却出现差异. 如在 DL-5 和 DL-11 点, 湖水中 $\delta^{18} \mathrm{O}$ 平均 值出现不同程度的偏正 (偏移幅度分别约为 $0.385 \%$ 和 $0.094 \%$, 当然同样可以忽略)（图 $4 \mathrm{~A} 、 \mathrm{~B}$, 表 2 ). 就 DL-4、DL-5、DL-9 和 DL-11 站点来看, 位于湖中部的 DL-4 点水体中 $\delta \mathrm{D} 、 \delta^{18} O$ 值偏负程度最为明显: 由上层 水体 $\left(0 \sim 1 \mathrm{~m}\right.$ ) 到底层水体 (7 9 m), $\delta \mathrm{D}$ 平均值由约 $-27.21 \%$ 偏负到约 $-33.45 \%$ (图 4A); $\delta^{18} \mathrm{O}$ 平均值则由 约 $1.21 \%$ 偏负到约 $-2.08 \%$ (图 4B). 相对地, 其他站点水体中 $\delta \mathrm{D} 、 \delta^{18} \mathrm{O}$ 值随水深偏移程度相对较小, 具体变 化趋势也存在一定程度的差异 (表 2).

由于采样点在达里湖中的位置差异, 受相应水体理化性质差异的影响, 导致在同一深度不同站点水体 的 $\delta \mathrm{D} 、 \delta^{18} \mathrm{O}$ 值也出现一定幅度的变化. 通过综合比较不同水深各个站点水体同位素值的变化 ( 以同一深度 至少存在 3 个样点为依据), 可以发现, 同一水深不同站点间 $\delta \mathrm{D}$ 值最大差异约为 $7.31 \%$, 出现在 $1.5 \mathrm{~m}$ 水深 处 (图 4a); $\delta^{18} \mathrm{O}$ 值最大差异约为 $1.32 \%$, 出现在 $8.5 \mathrm{~m}$ 水深处 (图 4b). 当然, 即使在同一站点, 随着水深的 增加, 水体 $\delta \mathrm{D} 、 \delta^{18} \mathrm{O}$ 值也会出现一定幅度的波动.

整体上, 达里湖夏季水体 $\delta \mathrm{D} 、 \delta^{18} \mathrm{O}$ 值随着水深增加逐渐呈现偏负的变化趋势. 其中, 水体 $\delta \mathrm{D}$ 值的变化 过程相对稳定, 在各个取样点由上层水体到底层水体对比过程中均为偏负变化趋势, 由表层水体到底层水 体整体偏负约 $1.40 \%$; 尽管在不同深度水体对比中 $\delta^{18} \mathrm{O}$ 值出现区域性的偏正变化, 不过由表层水体到底层 水体, $\delta^{18} \mathrm{O}$ 值整体上还是偏负约 $0.27 \%$ (表 2$)$. 
DL-5站点 $\delta \mathrm{D}$ 值/\%

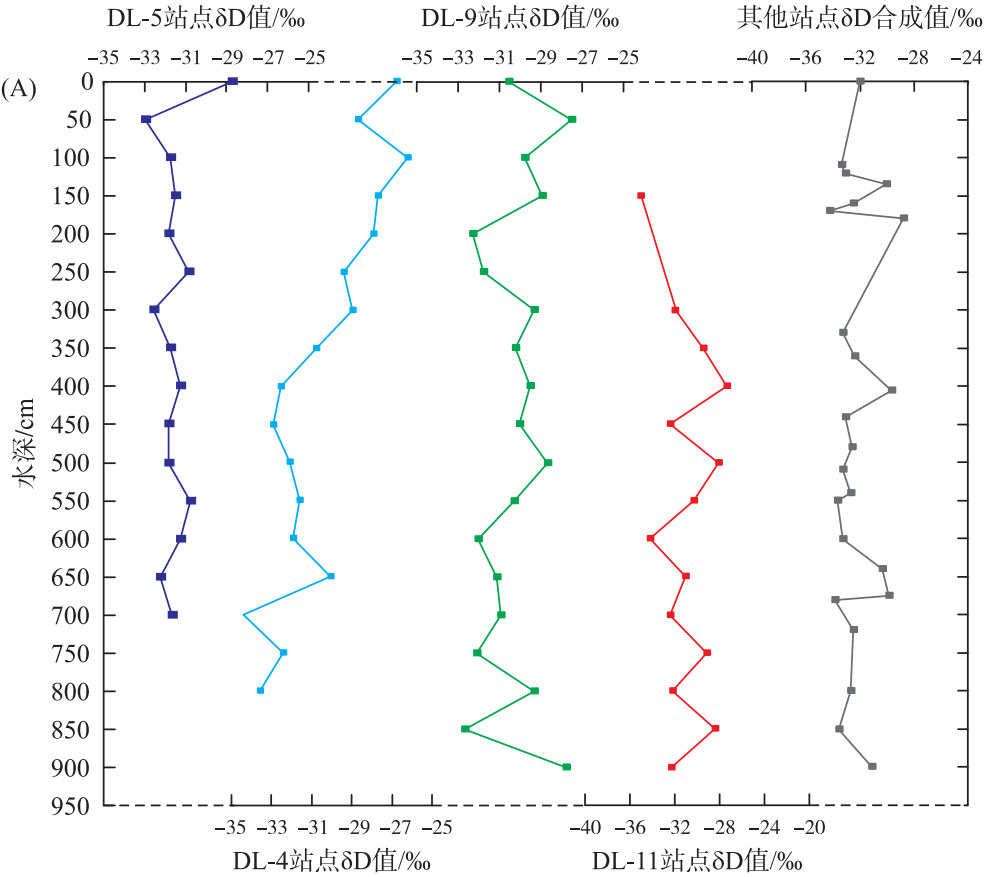

DL-5站点 $\delta^{18} \mathrm{O}$ 值/\%0

DL-9站点 $\delta^{18} \mathrm{O}$ 值/\%

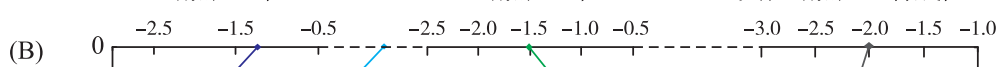

(B)

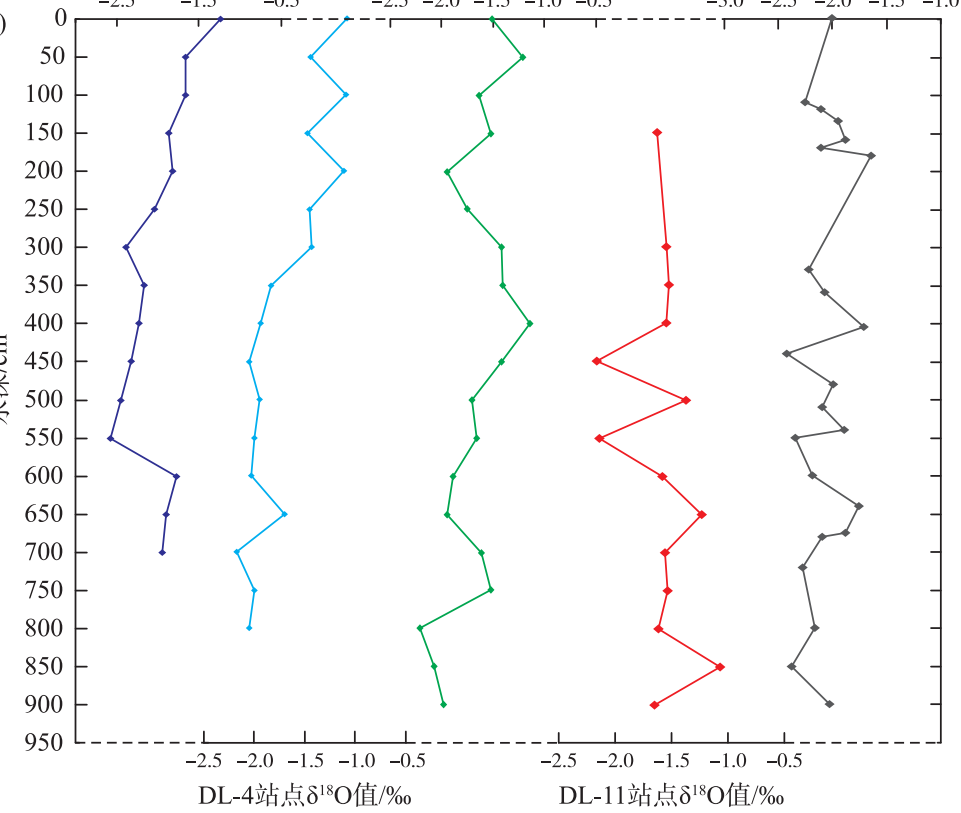

(a)

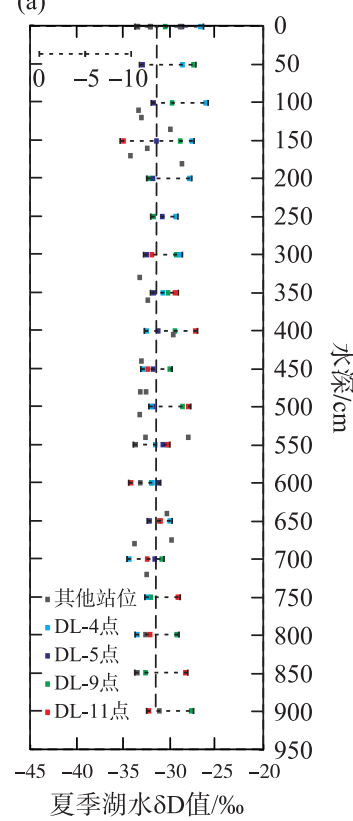

(b)

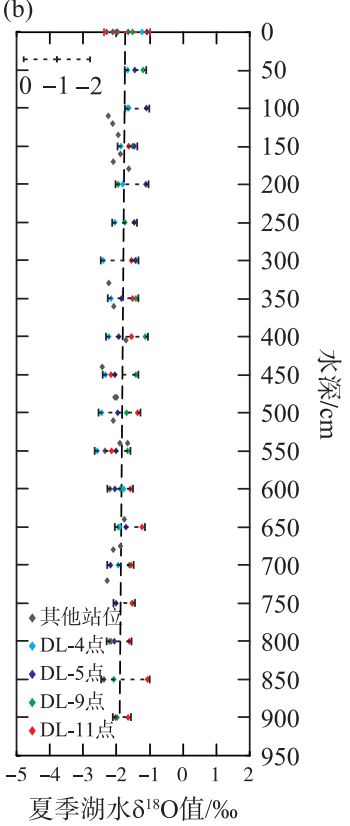

图 4 达里湖夏季水体稳定同位素值随水深变化情况 ( (A) 和 (a) 图为达里湖夏季不同取样点

$\delta \mathrm{D}$ 值随水深变化情况; (B) 和 $(b)$ 图为达里湖夏季不同取样点 $\delta^{18} \mathrm{O}$ 值随水深变化情况.

(a) 和 (b) 中黑色段划线代表同一深度不同采样点 (采样点个数 $\geqslant 3$ ) 间水体 $\delta \mathrm{D} 、 \delta^{18} \mathrm{O}$ 值的差异大小示例)

Fig.4 Stable isotope changes in different depths in summer water in Dali-nor Lake 
表 2 达里湖夏季不同深度水体 $\delta \mathrm{D} 、 \delta^{18} \mathrm{O}$ 值比较

Tab. 2 Changes of $\delta \mathrm{D}$ and $\delta^{18} \mathrm{O}$ in summer water in different depths of Dali-nor Lake

\begin{tabular}{ccccccc}
\hline 同位素值 & 样品深度 & DL-4 & DL-5 & DL-9 & DL-11 & 平均值 \\
\hline \multirow{2}{*}{$\delta \mathrm{D} / \% 0$} & $0 \sim 1 \mathrm{~m}$ & -27.2105 & -31.1603 & -29.2814 & - & -30.2183 \\
& $4 \sim 5 \mathrm{~m}$ & -32.4942 & -31.6446 & -29.4095 & -29.2723 & -31.1935 \\
& $7 \sim 9 \mathrm{~m}$ & -33.4530 & -31.6752 & -30.5481 & -30.8995 & -31.6172 \\
$\delta^{18} \mathrm{O} / \% 0$ & $0 \sim 1 \mathrm{~m}$ & -1.2107 & -1.5210 & -1.4531 & - & -1.6148 \\
& $4 \sim 5 \mathrm{~m}$ & -1.9829 & -2.3373 & -1.4233 & -1.6941 & -1.9170 \\
& $7 \sim 9 \mathrm{~m}$ & -2.0816 & -1.9523 & -1.8812 & -1.6000 & -1.8816 \\
\hline
\end{tabular}

“-”代表无有效数据.

\section{4 达里湖水体同位素垂向变化分析及影响因素}

达里湖是中国北方寒一早区典型的高原内陆封闭型湖泊, 主要靠大气降水、河流、地下水等补给, 区域年 均蒸发量远大于年均降水量, 而夏季达里湖水往往受到强烈蒸发作用的影响. 基于沉积物 $\mathrm{AMS}-{ }^{14} \mathrm{C}$ 测年结 果, 达里湖存在约 400 600 a 的碳库效应 ${ }^{[4-42]}$, 这从一方面说明达里湖水体交换并不迅速 (一般水深越深, 水体年龄可能越老, 即存在时间越长. 当然, 具体湖水年龄需要进一步测试分析确定). 同时, 加之达里湖水 体性质相对稳定, 流动缓慢 ${ }^{[23]}$. 因此, 不同深度湖水受到外来水体补给、二次蒸发作用等因素的影响程度可 能存在差异. 通过对比不同深度 (上层水体 $0 \sim 1 \mathrm{~m}$ 、中层水体 4 5 $\mathrm{m}$ 、底层水体 7 9 m) 水体稳定同位素组成 情况的变化, 可以揭示达里湖夏季水体同位素的垂向变化特征及影响因素, 也为进一步分析达里湖水文循 环过程提供基础资料.

随着水深的增加, 达里湖水体中 $\delta \mathrm{D} 、 \delta^{18} \mathrm{O}$ 值不仅出现逐渐偏负的变化趋势, 不同深度两者的关系 (这一 关系也被称为 “蒸发曲线” ) 也出现相应变化: 上层水体中 $\delta \mathrm{D}$ 与 $\delta^{18} \mathrm{O}$ 的相互关系为 $\delta \mathrm{D}=4.10 \delta^{18} \mathrm{O}-24.369$ $\left(R^{2}=0.7344\right)$, 中层水体中二者的相互关系为 $\delta \mathrm{D}=2.30 \delta^{18} \mathrm{O}-26.998\left(R^{2}=0.3195\right)$, 底层水体中二者的相互 关系为 $\delta \mathrm{D}=1.93 \delta^{18} \mathrm{O}-28.235\left(R^{2}=0.1643\right)$ (图 5a). 显然, 上层水体中 $\delta \mathrm{D}$ 和 $\delta^{18} \mathrm{O}$ 值的相互关系最为明显. 而水体越深, $\delta \mathrm{D}$ 和 $\delta^{18} \mathrm{O}$ 值变化的相互关系越不明显, 同时与大气降水中稳定同位素间的相互关系偏差越大 (图 5b). 由于 “斜率” 可以代表蒸发作用对水体同位素分馏的影响程度 ${ }^{[43]}$, 因此伴随深度增加而逐渐减小 的斜率和偏负的截距也说明达里湖夏季水体在部分继承区域大气降水中稳定同位素组成特征之后,一方面 受到持续蒸发作用引起的同位素不断富集作用影响, 另一方面又受到河流、地下水体补给等外来水体输人 导致的同位素贫化作用的影响. 而伴随水体深度增加, 湖泊上部水体与底层水体逐渐融汇整合, 最终导致湖 泊水体的稳定同位素组成关系出现相应的改变, 其 $\delta \mathrm{D} 、 \delta^{18} \mathrm{O}$ 值间的相互关系逐渐重组, 特别是底层水体中 $\delta D 、 \delta^{18} O$ 值逐渐偏负, 相互关系越来越不明显.

此外, 通过不同水体中 $\delta \mathrm{D} 、 \delta^{18} \mathrm{O}$ 值变化特征对比, 可以发现达里湖夏季不同深度水体的同位素值均分 布在全球“大气水线”和达里湖夏季 “大气水线”之下,且上层水体中稳定同位素的相互关系与大气降水、人 湖河流水体的同位素组成关系最为接近 (斜率相近, 图 5b), 表层水体与大气降水间的 $\delta \mathrm{D} 、 \delta^{18} \mathrm{O}$ 值偏移幅度 也最小 (表 2,3 ). 而伴随水深增加, 湖水和大气降水、河水的同位素组成关系的差异不断增大. 显然, 湖泊上 层水体受大气降水等外来水体输人的影响比较明显. 再者, 一方面, 达里湖夏季水体 $\delta \mathrm{D} 、 \delta^{18} \mathrm{O}$ 的平均值均比 大气降水、人湖河水及地下水中 $\delta \mathrm{D} 、 \delta^{18} \mathrm{O}$ 的平均值偏正 (表 3 ), 显示湖水受到了蒸发作用引起的稳定同位素 富集作用影响; 另一方面, 人湖河水中 $\delta \mathrm{D} 、 \delta^{18} \mathrm{O}$ 平均值又处于大气降水 (湖水)、浅层地下水体 $\delta \mathrm{D} 、 \delta^{18} \mathrm{O}$ 平均 值之间 (表 3), 即显示出河流输人对湖泊水体稳定同位素的稀释影响, 也显示出河流在地下水和湖水间的纽 带作用: 亮子河、沙里河、耗来河与贡格尔河水体主要由地下水形成, 经过沿途的蒸发、大气降水混人等水体 交换影响之后 (导致河流水体的稳定同位素值比地下水偏正, 比大气降水偏负, 表 3), 最终汇人达里湖 ${ }^{[23]}$, 对达里湖水体同位素组成关系产生影响.

在达里湖, 湖泊夏季水体的稳定同位素组成变化除受强烈蒸发作用的影响外, 还受到大气降水、河流、 


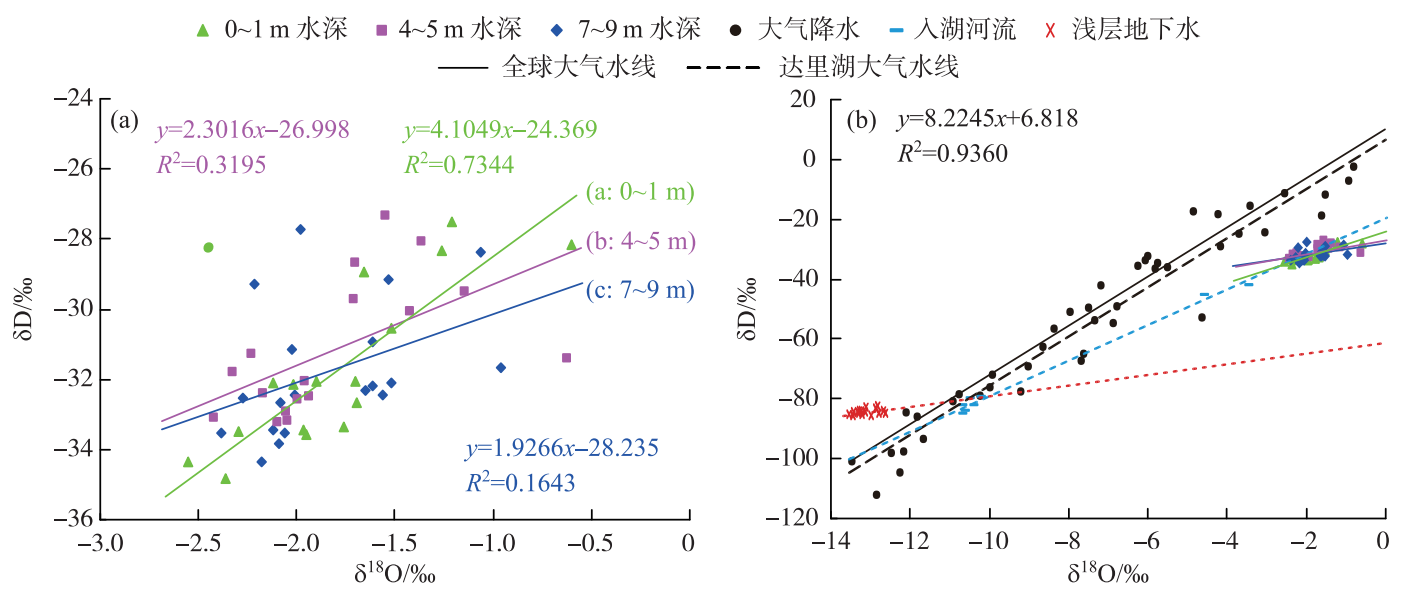

图 5 达里湖夏季不同水深及不同水体中 $\delta \mathrm{D}$ 和 $\delta^{18} \mathrm{O}$ 的相互关系特征

（（a）达里湖不同水深处水体中 $\delta \mathrm{D} 、 \delta^{18} \mathrm{O}$ 变化关系；(b) 达里湖不同水体中 $\delta \mathrm{D}$ 、

$\delta^{18} \mathrm{O}$ 变化关系, 图中公式为夏季大气降水中 $\delta \mathrm{D} 、 \delta^{18} \mathrm{O}$ 变化关系 $)$

Fig.5 Relationships between $\delta \mathrm{D}$ and $\delta^{18} \mathrm{O}$ in different water samples and layers in summer of Dali-nor Lake

地下水等补给输人的影响 ${ }^{[18]}$. 通过不同水体中稳 定同位素值的比较,可以发现达里湖夏季水体 $\delta \mathrm{D}$ 、 $\delta^{18} \mathrm{O}$ 平均值均明显比大气降水等其他水体中的平 均值偏正 (表 3). 这是因为基于达里湖不同站点 7 、 $8 、 9$ 月湖水样品中 $\delta \mathrm{D} 、 \delta^{18} \mathrm{O}$ 值的对比分析,发现夏 季强烈的蒸发作用会大部分抵消降水过程对湖泊 水体同位素组成的影响 ${ }^{[21]}$. 而随后经过夏季至冬 季冰封之前的持续蒸发作用(湖冰可以有效阻止蒸
表 3 达里湖区域不同水体中 $\delta \mathrm{D} 、 \delta^{18} \mathrm{O}$ 值变化

Tab.3 Changes of $\delta \mathrm{D}$ and $\delta^{18} \mathrm{O}$ values in different water samples in Dali-nor Lake

\begin{tabular}{ccccc}
\hline 样品 & 夏季湖水 & 大气降水 & 人湖河水 & 浅层地下水 ${ }^{*}$ \\
\hline$\delta^{18} \mathrm{O} / \% 0$ & -1.8045 & -7.3433 & -9.4994 & -12.5663 \\
$\delta \mathrm{D} / \%$ & -31.0097 & -53.5761 & -72.4268 & -81.3313 \\
\hline
\end{tabular}

*表示数据来源于参考文献 [7]. 发作用对湖水稳定同位素分馏的影响), 湖水中 $\delta \mathrm{D} 、 \delta^{18} \mathrm{O}$ 值往往会出现偏正变化: 在冬季, 无论湖冰还是冰 下水体, 其 $\delta \mathrm{D} 、 \delta^{18} \mathrm{O}$ 平均值均明显比夏季湖水中 $\delta \mathrm{D} 、 \delta^{18} \mathrm{O}$ 平均值偏正 ${ }^{[21]}$. 因此, 虽然达里湖夏季上层湖水中 $\delta \mathrm{D} 、 \delta^{18} \mathrm{O}$ 的相互关系较好且最接近大气降水中同位素组成特征, 但是持续的蒸发作用同时会对达里湖水体 的稳定同位素组成关系产生影响, 导致 $\delta \mathrm{D}$ 与 $\delta^{18} \mathrm{O}$ 间相互关系式的斜率和截距明显减小 (图 $5 \mathrm{~b}$ ); 而伴随河 流、地下水等补给源水体的持续输人, 最终导致短暂的大气降水过程对达里湖夏季水体中 $\delta \mathrm{D}$ 与 $\delta^{18} 0$ 值相 互关系的影响逐渐减弱: 在湖水表层和底层相互转化保存过程中, 水体中稳定同位素组成变化逐渐偏离大 气降水及河流水体中同位素组成特征 (表 3), 而不断趋近于地下水体中 $\delta \mathrm{D}$ 与 $\delta^{18} \mathrm{O}$ 值的相互关系 (图 5b). 当然, 对比达里湖不同区域底层水体中 $\delta \mathrm{D} 、 \delta^{18} \mathrm{O}$ 值的变化情况 (图 $4 \mathrm{a}, \mathrm{b}$ ), 可以发现不同区域底层水体 $\delta \mathrm{D}$ 、 $\delta^{18} \mathrm{O}$ 值的变化趋势并不一致,存在一定程度的区域特征, 且相对于表层水体, 不同区域底层水体间的 $\delta \mathrm{D}$ 、 $\delta^{18} \mathrm{O}$ 值差异相对较小, 这在一定程度上说明达里湖底层水体稳定同位素组成变化的影响因素和表层水体的 影响因素可能并不一致, 也解释了伴随湖泊水深增加, 水体中 $\delta \mathrm{D}$ 与 $\delta^{18} \mathrm{O}$ 值的相互关系逐渐变差这一现象.

总之, 在达里湖水体物理性质相对稳定, 水体流动缓慢的条件下, 达里湖上层水体中 $\delta \mathrm{D}$ 与 $\delta^{18} \mathrm{O}$ 值的相 互关系最接近大气降水中 $\delta \mathrm{D}$ 与 $\delta^{18} \mathrm{O}$ 值的变化关系, 但截距和斜率相对较小, 显示上层水体既受到大气降 水的稀释作用影响又受强烈蒸发作用的浓缩效应影响. 而伴随水深的增加, 蒸发作用及降水效应的影响逐 渐减弱, 不同深度水体的同位素组成关系逐渐开始重组: 相较于中层水体, 底层水体受到地下水补给等因素 的影响可能更加明显.

\section{5 结论}

在分析达里湖夏季不同深度水体典型理化指标及 $\delta \mathrm{D} 、 \delta^{18} \mathrm{O}$ 值变化特征的基础上,结合湖区大气降水、 
人湖河流、浅层地下水中 $\delta \mathrm{D} 、 \delta^{18} \mathrm{O}$ 值的变化, 对不同深度湖水稳定同位素组成关系进行讨论.

1) 达里湖水体温度、盐度等理化指标虽然随水深变化出现一定程度的偏移, 且同一深度不同区域水体 的理化指标也存在差异, 不过由于达里湖水体整体深度较浅, 这种偏移或差异并没有形成明显的 “跃层” (如 温跃层、盐跃层等). 因此,可以说达里湖夏季水体典型理化性质在空间变化上整体是相对稳定的.

$2)$ 达里湖区域夏季 “大气水线”为 $\delta \mathrm{D}=8.22 \delta^{18} \mathrm{O}+6.82\left(R^{2}=0.936\right)$, 显示大气降水中 $\delta \mathrm{D} 、 \delta^{18} \mathrm{O}$ 值变化既 受季风降水效应影响又受区域蒸发作用影响. 不同月份大气降水中 $d$ 值出现的明显偏移, 也进一步说明 $7 、 8$ 月大气降水同位素组成相对受大气降水过程的稀释效应影响强烈, 而 $6 、 9$ 月份则相对受蒸发作用引起的浓 缩效应更强烈.

$3)$ 达里湖夏季水体中 $\delta \mathrm{D}$ 值的变化过程相对稳定, 由表层水体到底层水体偏负约 $1.40 \% 0 ; \delta^{18} \mathrm{O}$ 值则在 部分区域不同深度水体中出现阶段性的偏正变化, 整体上由表层水体到底层水体偏负约 $0.27 \%$. 同时, 表层 水体中 $\delta \mathrm{D}$ 与 $\delta^{18} \mathrm{O}$ 值间相互关系最接近大气降水及人湖河流水体中 $\delta \mathrm{D}$ 与 $\delta^{18} \mathrm{O}$ 值的相互关系, 显示上层水 体受大气降水影响显著; 而底层水体中 $\delta \mathrm{D}$ 与 $\delta^{18} \mathrm{O}$ 值的相互关系则接近于地下水体中 $\delta \mathrm{D}$ 与 $\delta^{18} \mathrm{O}$ 值的相互 关系, 即达里湖夏季上层湖水和底层湖水中稳定同位素组成变化的影响因素存在差异. 整体上, 伴随水深的 增加, 蒸发作用及降水效应的影响逐渐减弱, 不同深度水体的同位素组成关系逐渐重组, 相较于中层水体, 底层水体可能受地下水补给过程等的影响更加明显.

致谢: 感谢内蒙古自治区达里诺尔湖国家级自然保护区生态旅游有限公司工作人员在采样过程中给予的 帮助.

\section{6 参考文献}

[ 1 ] Li YW, Han TC. Situation of lakes water resources and major environmental problems in Inner Mongolia. Inner Mongolia Environmental Protect, 2000, 12(2) : 17-21. [ 李亚威, 韩天成. 内蒙古湖泊水资源及主要环境问题. 内蒙古环境保 护, 2000, 12(2): 17-21.]

[ 2 ] Hu JR, Jiang FQ, Wang YJ et al. On the importance of research on the lakes in arid land of China. Arid Zone Research, 2007, 24(2) : 137-140. [ 胡汝瞕, 姜逢清, 王亚俊等. 论中国干旱区湖泊研究的重要意义. 干旱区研究, 2007, 24 (2): 137-140.]

[ 3 ] Yang GS, Ma RH, Zhang L et al. Lake status, major problems and protection strategy in China. J Lake Sci, 2010, 22 (6) : 799-810. DOI: 10.18307/2010.0601. [ 杨桂山, 马荣华, 张路等. 中国湖泊现状及面临的重大问题与保护策略. 湖泊科学, 2010, 22(6): 799-810.]

[ 4 ] Gu XH, Mao ZG, Ding HP et al. Progress and prospect of lake fishery in China. J Lake Sci, 2018, 30(1): 1-14. DOI: 10.18307/2018.0101. [ 谷孝鸿, 毛志刚, 丁慧萍等. 湖泊渔业研究: 进展与展望. 湖泊科学, 2018, 30(1): 1-14.]

[ 5 ] Wu QL, Jiang HL. China lake microbiome project. Bulletin Chinese Academic science, 2017, 32(3): 273-279. [ 吴庆龙, 江和龙. 中国湖泊微生物组研究. 中国科学院院刊, 2017, 32(3) : 273-279.]

[6] Xu YW, Kang SC, Zhang YL et al. A method for eatimating the contribution of evaporative vapor from the lake Nam Co to atmospheric vapor based on stable isotopes of water bodies. Chinese Science Bulletin, 2011, 56( 13) : 1042-1049. [徐彦 伟, 康世昌, 张玉兰等. 夏季纳木错湖水蒸发对当地大气水汽贡献的方法探讨: 基于水定同位素的估算. 科学通 报, 2011, 56(13): 1042-1049.]

[ 7 ] Zhen ZL, Li CY, Li WB et al. Characteristics of environmental isotopes of surface water and groundwater and their recharge relationships in lake Dali basin. J Lake Sci, 2014, 26(6) : 916-922. DOI:10.18307/2014.0614. [ 甄志否, 李畅 游, 李文宝等. 内蒙古达里诺尔湖流域地表水和地下水环境同位素特征及补给关系. 湖泊科学, 2014, 26(6): 916-922.]

[ 8 ] An CB, Chen FH. The pattern of Holocene climate change in the arid central Asia: a case study based on lakes. J Lake $S c i, 2009,21(3)$ : 329-334. DOI: 10.18307/2009.0303. [安成邦, 陈发虎. 中东亚干旱区全新世气候变化的西风模 式一以湖泊研究为例. 湖泊科学, 2009, 21(3) : 329-334.]

[ 9 ] Zhang YH, Wu YQ, Wen XH et al. Application of environmental isotopes in water cycle. Advance Water Science, 2006,17 (5) : 738-747. [张应华, 仵彦卿, 温小虎等. 环境同位素在水循环研究中的应用. 水科学进展, 2006, 17(5): 738-747.] 
[10] Gibson JJ, Reid R. Water balance along a chain of tundra lakes: A 20-year isotopic perspective. Journal of Hydrology, 2014, 519: 2148-2164. DOI: 10.1016/j.jhydrol.2014.10.011.

[11] Hepp J, Tuthorn M, Zech R et al. Reconstructing lake evaporation history and the isotopic composition of precipitation by a coupled $\delta^{18} \mathrm{O}-\delta^{2} \mathrm{H}$ biomarker approach. Journal of Hydrology, 2014, 519: 2164-2173. DOI: 10.1016/j. jhydrol.2014. 10.012 .

[12] West AG, February EC, Bowen GJ. Spatial analysis of hydrogen and oxygen stable isotopes ( “isoscapes”) in ground water and tap water across South Africa. Journal of Geochemical Exploration, 2014, 145(2) : 213-222.

[13] Price RM, Skrzypek G, Grierson PF et al. The use of stable isotopes of oxygen and hydrogen to identify water sources in two hypersaline estuaries with different hydrologic regimes. Marine \& Freshwater Research, 2012, 63(11) : 952-966.

[14] Brooks JR, Gibson JJ, Birks SJ et al. Stable isotope estimates of evaporation: inflow and water residence time for lakes across the United States as a tool for national lake water quality assessments. Limnology and Oceanography, 2014, 59(6) : 2150-2165.

[15] Good SP, Noone D, Bowen G. Hydrologic connectivity constrains partitioning of global terrestrial water fluxes. Science, 2015, 349: 175-177.

[16] Pu JB, Li JH, Wu X et al. Hydrogen and oxygen isotope characteristics controlled by thermal stratification effect in a subtropical reservoir, SW China. Advance Water Science, 2016, 27(4) : 561-567. [浦俊兵, 李建鸿, 吴夏等. 热分层效应 控制的水库水体氢氧同位素特征. 水科学进展, 2016, 27(4): 561-567.]

[17] Liu XX, Li CY, Li WB et al. The distribution and relationship if isotope and nutrient during freeze-up period in the lake Dalinuoer: A quantitative approach. J Lake Sci, 2015, 27(6) : 1159-1167. DOI:10.18307/2015.0622. [刘晓旭, 李畅 游, 李文宝等. 冰封期达里诺尔湖同位素与营养盐分布特征及关系的定量研究. 湖泊科学, 2015, 27 (6): 1159-1167.]

[18] Gibson JJ, Birks SJ, Yi Y. Stable isotope mass balance of lakes: a contemporary perspective. Quaternary Science Reviews, 2016, 131: 316-328

[19] Xu JZ, Xiao W, Xiao QT et al. Temporal dynamics of stable isotopic composition in Lake Taihu and controlling factors. Environment Science, 2016, 37(7) : 2470-2477. [徐敬争, 肖薇, 肖启涛等. 湖水氢氧同位素组分的时间变化特征及 影响因子分析. 环境科学, 2016, 37(7): 2470-2477.]

[20] Li WB, Li CY, Liu XX et al. Changes of stable oxygen and hydrogen isotopes and their responses to freezing process in Dali-Nor Lake in cold-arid areas of China. Earth Science-Journal of China University Geoscience, 2015, 40(12) : 2081-2090. [李文宝, 李畅游, 刘晓旭等. 寒旱区达里诺尔湖水体稳定氢、氧同位素变化对结冰过程的响应. 地球科学-地质大 学学报, 2015, 40(12): 2081-2090.]

[21] Ohba T, Hirabayashi J, Nogami K. D/H and ${ }^{18} \mathrm{O} /{ }^{16} \mathrm{O}$ ratios of water in the crater lake at Kusatsu-Shirane volcano, Japan. Journal of Volcanology \& Geothermal Research, 2000, 97(1) : 329-346.

[22] Zhang XP, Yao TD. Estimation of lake evaporation by stable isotopic ratio. Journal of Glaciology and Geocryology, 1997, 19(2)：161-167. [ 章新平，姚檀栋. 利用稳定同位素比率估计湖泊的蒸发. 冰川冻土，1997，19(2)：161-167.]

[23] Liu ZJ. Tests of hydrodynamics and hydrogen and oxygen stable isotopes in Lake Dalinuoer[Dissertation]. Hohhot: Inner Mongolia Agricultural University, 2015. [刘志娇. 达里诺尔湖水动力条件及氢氧稳定同位素试验研究 [学位论文]. 呼和浩特: 内蒙古农业大学, 2015.]

[24] Li WB, Li CY, Jia DB et al. Stable isotope changes of summer precipitation in Middle Inner Mongolia. Arid Zone Research, 2017, 34(6): 1214-1221. [李文宝, 李畅游, 贾德彬等. 内蒙古中部地区夏季大气降水同位素变化特征. 干 旱区研究, 2017, 34(6): 1214-1221.]

[25] Xiao JL, Si B, Zhai DY et al. Hydrology of Dali Lake in central-eastern Inner Mongolia and Holocene East Asian monsoon variability. Journal of Paleolimnology, 2008, 40(1) : 519-528.

[26] Zhen ZL, Zhang S, Shi XH et al. Research on the evolution of Dali lake area based on the remote sensing technology. China Rural Water and Hydropower, 2013, 7: 6-9. [ 甄志否, 张生, 史小红等. 基于遥感技术的达里诺尔湖湖面演化研 究. 中国农村水利水电, 2013, 7: 6-9.]

[27] Craig H. Isotopic variations in meteoric water. Science, 1961, 133: 1702-1703.

[28] Yin G, Ni SJ eds. Isotope geochemistry. Beijing: Geological Publishing House, 2009. [尹观, 倪师军. 同位素地球化学. 北京: 地质出版社, 2009.] 
[29] Zhang XP, Yao TD. Distributional features of $\delta^{18} \mathrm{O}$ in precipitation in China. Acta Geographica Sinica, 1998, 53(4): 356-364. [章新平, 姚檀栋. 我国降水中 $\delta^{18} \mathrm{O}$ 的分布特点. 地理学报, 1998, 53(4):356-364.]

[30] Liu JR, Song XF, Yuan GF et al. Stable isotopic compositions of precipitation in China. Tellus Series B-Chemical \& Physical Meteorology, 2014, 66(66) : 39-44.

[31] Li YJ, Zhang MJ, Wang SJ et al. Progress of the research of stable isotope in precipitation in China: A review. Journal of Glaciology and Geocryology, 2011, 33(3): 624-633. [李亚举, 张明军, 王圣杰等. 我国大气降水中稳定同位素研究 进展. 冰川冻土, 2011, 33(3): 624-633.]

[32] Chen ZX, Ch J, Guo PW et al. Distribution characters and its control factors of stable isotope in precipitation over China. Transactions of Atmospheric Sciences, 2010, 33(6): 667-679. [ 陈中笑, 程军, 郭品文等. 中国降水稳定同位素的分布 特点及其影响因素. 大气科学学报, 2010,33(6): 667-679.]

[33] Liu ZF, Tian LD, Yao TD et al. Spatial distribution of $\delta^{18} \mathrm{O}$ in precipitation over China. Chinese Science Bulletin, 2009, 54(6): 804-811. [刘忠方, 田立德, 姚檀栋等. 中国大气降水中 $\delta^{18} \mathrm{O}$ 的空间分布. 科学通报, 2009, 54(6): 804-811.]

[34] Hua MQ, Zhang XP, Yao TC et al. Experiments and simulations of water stable isotopes fractionation in evaporation pan. Tropical Geography, 2017, 37(4): 501-511. [华明权, 章新平, 姚天次等. 蒸发血蒸发过程中水稳定同位素分馏的 实验与模拟. 热带地理, 2017, 37(4): 501-511.]

[35] Zhang XP, Liu JM, Sun WZ et al. The oxygen isotope in precipitation and relationship with meteorological factors in Southwest China. Science China: Series D: Earth Science, 2006, 36(9): 850-859. [章新平, 刘晶沝, 孙维贞等. 中国西南地 区降水中氧稳定同位素比率与相关气象要素之间关系的研究. 中国科学: D 辑: 地球科学, 2006, 36 (9): 850-859. ]

[36] Wu JK, Ding Y, Ye B et al. Spatio-temporal variation of stable isotopes in precipitation in the Heihe River Basin, Northwestern China. Environmental Earth Science, 2010, 61(6) :1123-1134.

[37] Zhang XP, Liu JM, Nakawo M et al. Vapor origins revealed by Deuterium excess in precipitation in Southwest China. Journal of Glaciology and Geocryology, 2009, 31(4): 613-619. [章新平, 刘晶沝, 中尾正义等. 我国西南地区降水中过 量氝指示水汽来源. 冰川冻土, 2009, 31(4): 613-619.]

[38] Pang SG, Zhao SK, Wen R et al. Spatial and temporal variation of stable isotopes in precipitation in the Haihe River basin. Chinese Science Bulletin, 2015, 60(13) : 1218-1226. DOI: 10.1360/N972014-01040. [ 庞朔光, 赵诗坤, 文蓉等. 海河 流域大气降水中稳定同位素的时空变化. 科学通报, 2015, 60(13): 1218-1226.]

[39] Dansggaard W. Stable isotopes in precipitation. Tellus, 1964, 6: 436-468.

[40] Zhang GL, Jiao YM, He LP et al. Hydrogen and oxygen isotopes in precipitation in Southwest China: progress and prospects. Journal of Glaciology and Geocryology, 2015, 37(4) : 1094-1103. [张贵玲, 角媛梅, 何礼平等. 中国西南地区 降水氢氧同位素研究进展与展望. 冰川冻土, 2015, 37(4): 1094-1103.]

[41] Liu SH, Deng CL, Xiao JL et al. Insolation driven biomagnetic response to the Holocene Warm Period in semi-arid East Asia. Science Report, 2015, 5: 8001-8007.

[42] Liu SH, Deng CL, Xiao JL et al. High-resolution enviromagnetic records of the last deglaciation from Dali Lake, Inner Mongolia. Palaeogeography, Palaeoclimatology, Palaeoecology, 2016, 454: 1-11.

[43] Stenni B, Scarchilli C, Masson-Delmotte V et al. Three-year monitoring of stable isotopes of precipitation at Concordia Station, East Antarctica. The Cryosphere, 2016, 10(5) : 2415-2428. 